\title{
Modeling the Relationships among Academic Identity, Psychological Sense of School Membership, and Teacher Support: The Mediating Role of Academic Adjustment in Academic Performance
}

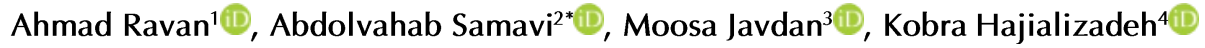 \\ 1 PhD Student in Educational Psychology, Bandar Abbas Branch, Islamic Azad University, Bandar Abbas, Iran \\ 2 Associate Professor, Department of Educational Sciences, Faculty of Human Sciences, University of Hormozgan, Bandar \\ Abbas, Iran \\ 3 Assistant Professor, Department of Psychology, Faculty of Human Sciences, University of Hormozgan, Bandar Abbas, Iran \\ ${ }^{4}$ Associate Professor of Psychology, Faculty of Human Sciences Faculty, Bandar Abbas Branch, Islamic Azad University, \\ Bandar Abbas, Iran
}

*Corresponding author: Abdolvahab Samavi, Department of Educational Sciences, Faculty of Human Sciences, University of Hormozgan, Bandar Abbas, Iran Email: samavi@hormozgan.ac.ir

Received: 29 Jan. 2020

Accepted: 26 May. 2020 ePublished: 01 Nov. 2020

\begin{abstract}
Background and Objective: This study was conducted to model the relationships of academic identity, psychosocial sense of school membership, and teacher support with academic performance by the mediating role of academic adjustment.

Materials and Methods: In this cross-sectional research, structural equation modeling (SEM) was employed to analyze the relationships. The statistical sample of the study $(n=422)$ were students selected by multi-stage cluster sampling method. The instruments used to gather the necessary data were the following questionnaires: Adjustment Inventory for School Students, Academic Identity Status Scale, Psychological Sense of School Membership Scale, and Teacher Emotional Support Scale. Furthermore, the student's grade point average in the current semester was considered as a measure of academic performance. The collected data were analyzed in AMOS software (version 24) using path analysis and SEM.

Results: The direct affecting analysis results revealed that the variables of moratorium identity and achievement identity, psychological sense of school membership, and academic adjustment each had a direct significant effect on students' academic performance $(\mathrm{P}<0.05)$. However, there was no significant relationship between teacher affective support and students' academic performance $(P>0.05)$. The results of the indirect-affecting analysis showed that such variables as moratorium, diffusion, and achievement identity, psychological sense of school membership, and teacher affective support by the mediating role of academic adjustment had a significant effect on academic performance $(\mathrm{P}<0.05)$.

Conclusion: The results showed that besides the teacher affective support, some aspects of academic identity, psychological sense of school membership, and academic adjustment had a significant effect on students' academic performance. Therefore, it is recommended to develop programs based on the variables of this study to increase students' academic performance.

Keywords: Academic adjustment, Academic identity, Academic performance, School membership, Teacher support
\end{abstract}

\section{Background}

The education system is one of the largest and most extensive systems within a society determining the destiny of that society in the long run. Academic performance affects crucial aspects of people's lives, such as pursuing higher education levels, getting a decent job, achieving higher social status, and gaining more satisfaction [1]. In addition, identity, as one of the personality traits, plays a vitally important role in academic performance. [2]. In this regard, schools provide opportunities to help individuals making better choices in their lives and build sustainable identities. Moreover, they develop a framework for decision-making, problem-solving, and dealing with regular problems [3].

Academic identity is a form of personal identity that defines oneself in terms of education [4]. In other words, academic identity is the process of consciously responding to each individual's academic position, achieving which can enhance academic adjustment [5]. According to Gazidari et 
al. (2016), moratorium academic identity and academic identity diffusion have a positive significant relationship with academic identity diffusion [6]. When students develop the feeling of being a part of a school and their psychological belongingness is being confirmed, they are more likely to get involved in school-related affairs. Regarding this, academic performance provides the best definition for this type of belongingness [7].

The development of a psychological sense of school membership creates favorable conditions for students to establish affective, cognitive, and social relationships, as well as getting more engaged in academic and cultural activities, resulting in academic performance [8]. Gray (2017) concluded that psychological membership in classroom influences students' motivation and academic performance [9]. Students who had a high sense of school belongingness and received affective support from principals and teachers had greater motivation to progress and therefore better academic performance [10]. It is undoubtedly true that since students spend the most of their school time under the teachers' supervision, the type of the relationship that teacher builds with students affects the quality of instructional materials and non-instructional duties [11].

Another central factor affecting the quality of the learning environment is the teacher's affective support. The effects of this factor are so extensive that they significantly influence the students' academic, affective, behavioral, and motivational outcomes at school [12]. The researchers found that if teachers provide more affective, educational, and social support, students will gain and show more affective skills [13]. Therefore, the teacher's affective support plays a significant role in students' enjoyment and academic achievement [14].

However, the relationship between the variables mentioned and academic performance is not linear since some of these variables may play a mediating role. In this study, the academic adjustment variable is considered a mediating variable. Highly academic adjustment enables students to successfully adapt to school and academic challenges as well as producing remarkable academic performance [15]. The hypothesized model of the current study has been presented in Figure 1.

\section{Objectives}

The fundamental question of the present study is whether the relationships of academic identity, psychosocial sense of school membership, and teacher support with academic performance by the mediating role of academic adjustment has a fit index.

\section{Materials and Methods}

This correlation research was conducted using the structural equation modeling (SEM) technique to analyze its structural relationships. The statistical population consisted of all high school students in Larestan, Fras Province, Iran, during the school year of 2018-2019. A multistage cluster sampling

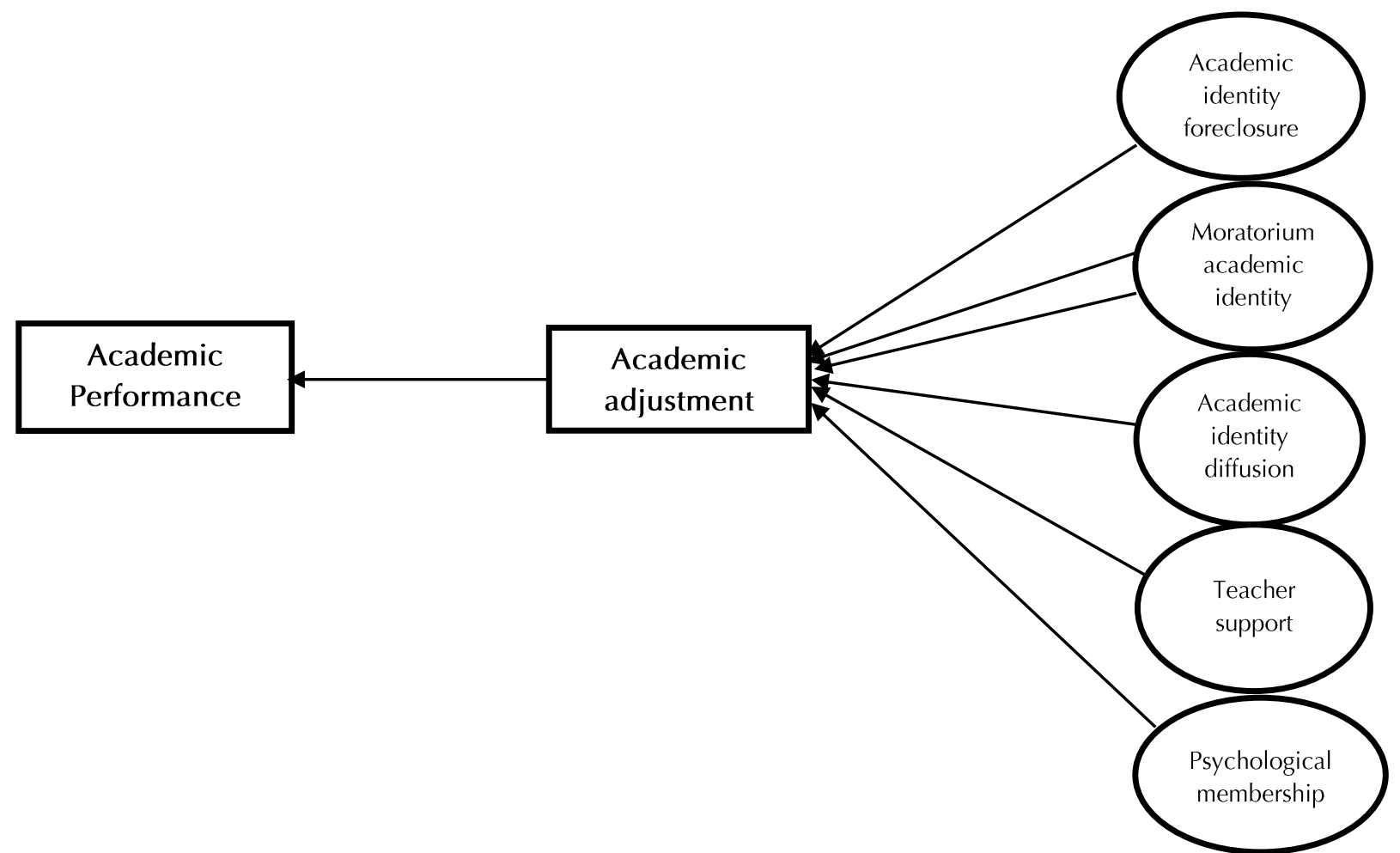

Figure1. Hypothesized model of the relationships of academic identity, psychological sense of school membership, and teacher support with academic performance by the mediating role of academic adjustment 
method was adopted for the collection of samples. The study sample was calculated as 422 based on Klein's (2010) method [16]. Based on this method, we should have 40 observations (participants) per variable. Since we had ten variables, the sample size was 422. To perform the sampling process, initially, four girls' schools and four boys' schools $(n=8)$ were randomly selected from Larestan's secondary schools. Subsequently, from each of these schools, three classes were randomly selected as the sample. The necessary data were collected using questionnaires, namely the Adjustment Inventory for school students (1993), Academic Identity Status Scale, Psychological Sense of School Membership Scale, and Teacher Emotional Support Scale. Moreover, the students' grade point average in the current semester was used as a measure of academic performance, which was standardized using the $z$-score. The inclusion criteria in this study were: 1) willing to participate in the study, 2) studying in a secondary high school in Larestan during the school year of 2017-2018, and 3) having physical and mental ability to participate in the study. On the other hand, the students who were reluctant to complete the questionnaires or withdrew from the study at any research stage were excluded. Furthermore, the participants were informed about the confidentiality of their personal information. Finally, informed consent was obtained from all students. The gathered data were analyzed in AMOS software (version 24) using path analysis and SEM.

\section{Instruments}

Adjustment Inventory for School Students

This questionnaire, developed by Sinha and Singh in 1993 [17], is a 60-item questionnaire with two response alternatives 'Yes' and 'No'. This instrument distinguishes good from poor students in three areas of adjustment, namely emotional, social, and educational. The rage of the scores in this questionnaire is $0-1$. The reliability coefficient of this test, confirmed by Sinha and Singh, was reported to be 0.95 and 0.93 , using the split-half and test-retest methods, respectively [16]. Fooladchang (2006) also evaluated the reliability of this questionnaire using Kuder-Richardson and testretest methods, rendering the coefficients of 0.89 and 0.82, respectively [18]. Saghi and Rajaei (2008) reported the reliability coefficient of this test as an acceptable value [19]. Among the three areas of the adjustments measured by the questionnaire, only the educational adjustment was examined in the present study. The reliability coefficient of the questionnaire for educational adjustment was obtained at 0.91 using the Cronbach's alpha coefficient method.

Academic Identity Status Scale

The questionnaire developed by Rahiminezhad et al. (2011) was used to measure the academic identity of the subjects. This instrument includes 16 items evaluating four academic identity statuses (i.e., achieved, moratorium, foreclosure, and diffused in the content of academic issues). The results of this questionnaire indicated that it could explain $56 \%$ of the variance in academic identity. In addition, the reliability of this scale has been reported acceptable [20]. In the present study, the Cronbach's alpha coefficient of this research tool was obtained at 0.83 .

Psychological Sense of School Membership Scale The questionnaire designed by $\mathrm{Ye}$ and Wallace (2014) was used to measure youths' perceptions of belonging and psychological engagement in school [21]. The 18-item questionnaire measures four dimensions, namely school staff communication, communication with friends, communication with teachers, and negative perceptions of school. Factorial analysis indicated the validity of four dimensions of the questionnaire (0.68). The reliability of this instrument was confirmed with the Cronbach's alpha coefficient calculated as 0.70-0.84. [21]. In the present study, the Cronbach's alpha reliability coefficient was obtained at 0.92 for all items.

\section{Teacher Emotional Support Scale}

In the present study, the questionnaire developed by Sakiz (2007) was employed to measure students' perceived teacher emotional support [22]. This 9item questionnaire is scored on a five-point Likert scale (strongly disagree $=1$ to strongly agree $=5$ ). The validity and reliability of the questionnaire were reviewed and verified by Sakiz (2007) [22]. Sadat Hosseyni and Khayer (2010) reported the reliability of this instrument calculated by Cronbach's alpha coefficient $(\alpha=0.79)$. Furthermore, the validity of this scale has been approved based on factor analysis [23]. The reliability of the instrument was confirmed using Cronbach's alpha coefficient $(\alpha=0.84)$.

Results

Table 1 summarizes the mean, minimum, and maximum scores of the research variables calculated for subjects of the study.

Among the research variables, the highest correlation coefficient was related to the relationship between teacher support and psychological sense of school membership $\left(\mathrm{r}^{2}=0.28, \mathrm{P}<0.001\right)$ (Table 2). Figure 2 
Table 1. Descriptive indices of research variables

\begin{tabular}{|c|c|c|c|c|c|}
\hline Variables & & Mean & SD & Min & $\operatorname{Max}$ \\
\hline \multirow{4}{*}{ Academic identity } & Achievement & 16.75 & 4.32 & 5 & 25 \\
\hline & Diffusion & 9.79 & 3.46 & 4 & 20 \\
\hline & Foreclosure & 9.73 & 2.65 & 3 & 15 \\
\hline & Moratorium & 11.49 & 3.06 & 4 & 20 \\
\hline \multicolumn{2}{|c|}{ Psychological sense of school membership } & 63.43 & 10.53 & 22 & 88 \\
\hline \multicolumn{2}{|c|}{ Teacher support } & 30.56 & 6.19 & 9 & 45 \\
\hline \multicolumn{2}{|c|}{ Academic adjustment } & 28.44 & 3.27 & 22 & 50 \\
\hline \multicolumn{2}{|c|}{ Academic performance } & 16.31 & 3.69 & 11 & 20 \\
\hline
\end{tabular}

Table 2. Correlation matrix between studied variables

\begin{tabular}{|c|c|c|c|c|c|c|c|c|c|}
\hline \multicolumn{2}{|l|}{ Variables } & 1 & 2 & 3 & 4 & 5 & 6 & 7 & 8 \\
\hline \multirow{4}{*}{$\begin{array}{l}\text { Academic } \\
\text { identity }\end{array}$} & Achievement & 1 & & & & & & & \\
\hline & Diffusion & $-0.22^{* *}$ & 1 & & & & & & \\
\hline & Foreclosure & 0.11 & $-0.12^{*}$ & 1 & & & & & \\
\hline & Foreclosure & $0.12 *$ & $0.23^{* *}$ & $-0.11^{* *}$ & 1 & & & & \\
\hline \multicolumn{2}{|c|}{ Psychological sense of school membership } & $0.37^{* *}$ & $-0.29 * *$ & $0.34^{* *}$ & $-016^{* *}$ & 1 & & & \\
\hline \multicolumn{2}{|c|}{ Teacher support } & $0.36^{* *}$ & $-0.26^{* *}$ & $0.28^{* *}$ & 0.05 & $0.65^{* *}$ & 1 & & \\
\hline \multirow{2}{*}{\multicolumn{2}{|c|}{ Academic adjustment }} & $0.38^{* *}$ & $-0.35^{* *}$ & $0.34^{* *}$ & $-0.34^{* *}$ & $0.49 * *$ & $0.48^{* *}$ & 1 & \\
\hline & & $0.21^{* *}$ & $-0.14^{* *}$ & $0.19 * *$ & $-0.20^{* *}$ & $0.28^{* *}$ & $0.22^{* *}$ & $0.44^{* *}$ & 1 \\
\hline
\end{tabular}

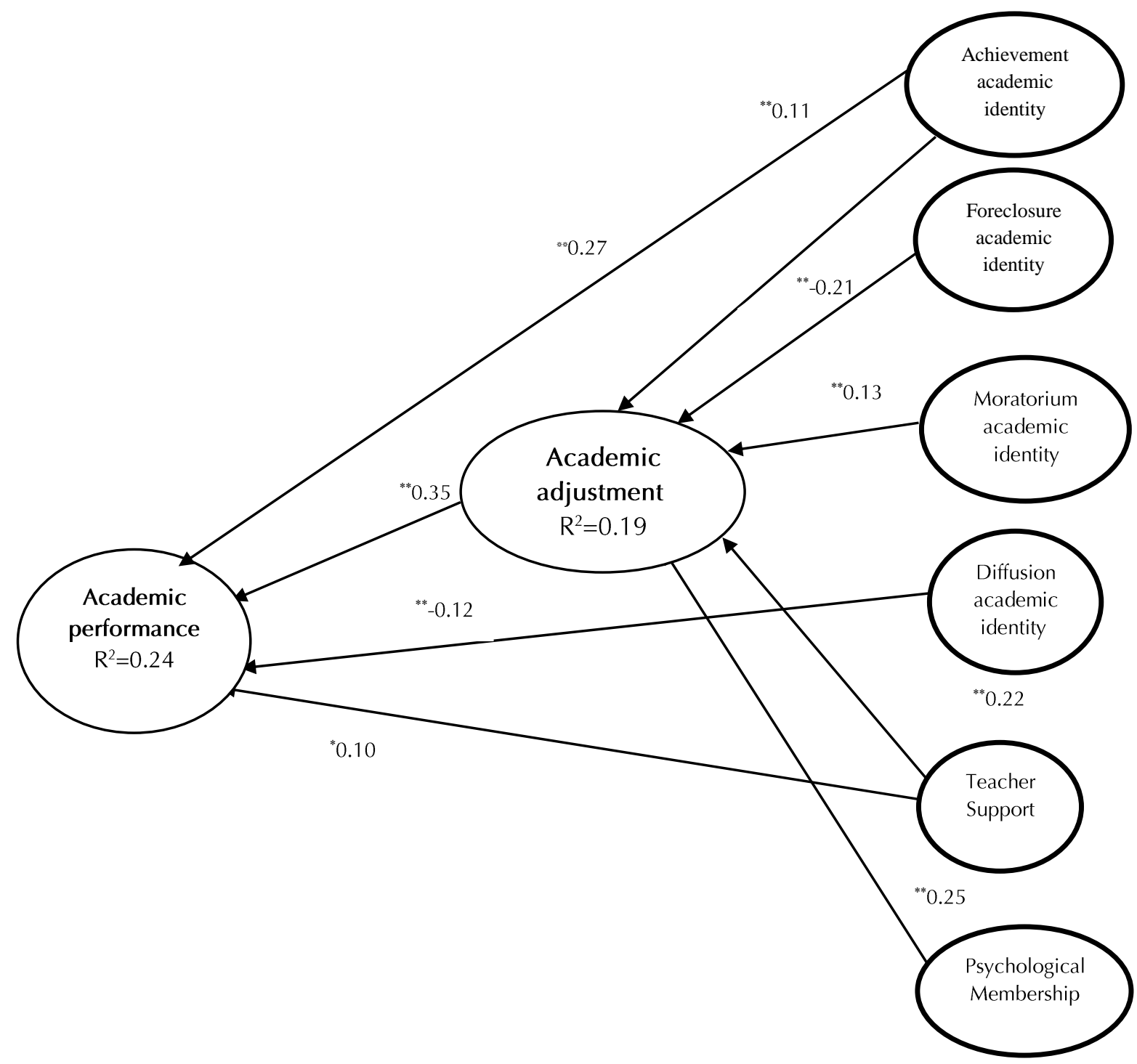

Figure 2. Proposed model of the relationships of academic identity, psychological sense of school membership, and teacher support with academic performance by the mediating role of academic adjustment 
depicts the results of applying the SEM analysis to test the research model in general. It should be noted that in this figure, significant lines were mapped.

Kolmogorov-Smirnov test was used to check the normality of the data. The results revealed that the data have a normal distribution and can be used for parametric analysis. As is shown in Table 3, all fit indices are higher than 0.90 indicating that the developed model has an appropriate fit. The root mean square error of approximation was calculated as 0.06 . Since the value of less than 1 is desirable for this index, this model is within an acceptable range for this index showing that the developed model is well-fitted.

The direct effects of the research variables are tabulated in Table 4.

\section{Direct Effects}

The results of Table 4 show that moratorium academic identity $(\beta=-0.12, P=0.008)$ and academic identity achievement significantly anticipate academic performance $(\beta=0.27, \quad \mathrm{P}=0.001)$. Moreover, the results indicated that the psychological sense of school membership could significantly predict students' academic performance $(\beta=0.10, \mathrm{P}=0.03)$.

\section{Indirect Effects}

According to the findings presented in Table 5, there are some significant indirect relationships between identity status and academic performance by the mediating role of academic adjustment. In addition, our results showed that the psychological sense of school membership by the mediating role of academic adjustment had a significant indirect effect on academic performance. The same results were found regarding the effect of teacher emotional support on academic performance by academic adjustment considered as the mediating role.

Table 3. Fit indices of the final research model

\begin{tabular}{lcccccccc}
\hline Index & $\mathbf{d f} / \boldsymbol{x}$ & GFI & AGFI & NFI & TLI & CFI & RMSEA & Pclose \\
\hline Finding & 2.12 & 0.94 & 0.92 & 0.92 & 0.91 & 0.91 & 0.059 & 0.16 \\
\hline
\end{tabular}

Table 4. Direct effect of variables in research model

\begin{tabular}{|c|c|c|c|c|c|}
\hline Variables & Estimated value & Standard Error & B & $\mathrm{t}$ & $\mathrm{P}$ \\
\hline Achievement identity & 0.08 & 0.03 & 0.11 & 2.62 & 0.009 \\
\hline Diffusion identity & -0.17 & 0.04 & -0.21 & -4.78 & 0.001 \\
\hline Foreclosure identity & 0.14 & 0.05 & 0.13 & 3.04 & 0.002 \\
\hline Moratorium identity & 0.06 & 0.04 & 0.06 & 1.38 & 0.16 \\
\hline Psychological sense of school membership & 0.06 & 0.01 & 0.22 & 5.12 & 0.001 \\
\hline Teacher support & 0.12 & 0.02 & 0.25 & 5.81 & 0.001 \\
\hline Academic adjustment & 0.20 & 0.02 & 0.35 & 7.37 & 0.001 \\
\hline Moratorium identity & -0.06 & 0.01 & -0.12 & -2.63 & 0.008 \\
\hline Foreclosure identity & 0.009 & 0.03 & -0.05 & -0.33 & 0.73 \\
\hline Diffusion identity & -0.02 & 0.03 & -0.04 & -0.93 & 0.34 \\
\hline Achievement identity & 0.34 & 0.02 & 0.27 & 6.11 & 0.001 \\
\hline Psychological sense of school membership & 0.01 & 0.07 & 0.10 & 2.13 & 0.03 \\
\hline Teacher support & 0.01 & 0.01 & 0.04 & 0.86 & 0.38 \\
\hline
\end{tabular}

Table 5. Direct and indirect standardized coefficients and total effects of research variables

\begin{tabular}{|c|c|c|c|c|c|c|}
\hline Variables & Direct effect & $\mathbf{P}$ & Indirect effect & $\mathbf{P}$ & Total effect & $\mathbf{P}$ \\
\hline Teacher support & 0.04 & 0.38 & 0.09 & 0.003 & 0.13 & 0.002 \\
\hline Psychological membership & 0.10 & 0.03 & 0.08 & 0.003 & 0.18 & 0.01 \\
\hline Moratorium identity & -0.12 & 0.008 & 0.02 & 0.17 & 0.14 & 0.02 \\
\hline Foreclosure identity & -0.05 & 0.73 & -0.05 & 0.01 & -0.06 & 0.34 \\
\hline Diffusion identity & -0.04 & 0.34 & -0.07 & 0.003 & -0.03 & 0.46 \\
\hline Achievement identity & 0.27 & 0.001 & 0.04 & 0.04 & 0.31 & 0.01 \\
\hline Academic adjustment & 0.35 & 0.001 & - & - & 0.35 & 0.001 \\
\hline
\end{tabular}

\section{Discussion}

This study was conducted to model the relationships of academic identity, psychological sense of school membership, and teacher affective support with academic performance by the mediating role of academic adjustment. The results revealed that moratorium identity and achievement identity can significantly predict students' academic performance. These results are in line with those of studies performed by Chorba et al. (2012) [24] and Gazidari et al. (2015) [6]. Adolescence is the period of transition from childhood to independence and adolescent responsibilities. During this period, young people go through many changes moving into physical maturity. These various changes make adolescents face multiple problems in adapting 
themselves to society and acquiring a healthy identity $[25,26]$.

Based on the result of the current study, the psychological sense of school membership can positively and significantly predict students' academic performance. The results of a study carried out by Peng et al. (2011) pointed out that the sense of school belonging can increase flexibility, self-esteem, and well-being in students, which in turn, can significantly improve students' academic performance [27]. On the other hand, a poor sense of school belonging is associated with academic failure, behavioral disorders, substance use, truancy, delinquency, as well as dropping out of school [28]. Adolescents who form strong social bonds with schools are more likely to engage in social behaviors, develop their educational potential, and are less prone to suffer from behavioral disorders than those who fail to build such bonds [29].

The results of this study also indicated that the relationship between teacher affective support and students' academic performance was not significant. These results are consistent with those of studies conducted by Wentzel et al. (2010) [30], Hughes and Kwok (2007) [31], and Sharhani (2016) [32]. Students' perceptions of their teachers' perceptions have long been regarded as an important dimension of the classroom atmosphere. Moreover, the findings of the present research revealed that academic adjustment can predict students' academic performance both positively and significantly. Perera et al. (2015) [33] and Soleimanifar and Shabani (2013) [34] found the same results in their studies. Academic adjustment reflects learners' ability in adapting to educational conditions and roles imposed by a school as a social entity. This type of adjustment includes school satisfaction, academic achievement, teacher interest, communication with other students, and school staff' views on school performance.

According to the findings of the present study, there is a significant indirect effect of moratorium identity, diffusion, and achievement identity on academic performance by the mediating role of academic adjustment. However, the indirect effect of foreclosure identity through mediating variables on academic performance was not significant. These results are compatible with the results of studies conducted by Chorba et al. (2012), [24] Beaumont (2009), [35], and Gazidari et al. (2016) [6]. To elaborate, it can be said that examining the components of academic identity can reveal their association with academic adjustment and affective well-being, consequently with academic performance.

Adolescents with an informational identity style are involved in the process of active self-inquiry, including seeking out, processing, and evaluating self-relevant information. In this process, the student or adolescent develops a cognition, not superficial and transient, helping them to understand the school properly. The result of this would be an increase in their adaptation and psychological well-being ultimately leading to improved academic performance [35]. In other words, acquiring the achievement identity enhances an individual's well-being and adjustment which ultimately improves academic performance. On the other hand, adolescents with a normative identity style act in a normative manner, and are always keen to internalize the values of reference groups, such as a particular religious school [24]. Regarding this, adolescents with a diffusion identity style avoid as much as possible being exposed to identity issues. Therefore, their behavior is regulated by situational and momentary factors, and they benefit less from cognitive strategies [35].

Other results of the current study indicated that the indirect effect of the psychological sense of school membership on academic performance by the mediating role of academic adjustment is significant. These results are consistent with those found by Gray (2017) [9] and Mirzabeigi et al. (2018) [10]. The sense of belonging to a school is defined as feeling accepted as a member of school. Students with such feelings are more motivated to participate in academic activities and develop a sense of being influential in classroom activities. Therefore, the development of a sense of belonging to the school is important due to its association with positive and negative adaptation outcomes.

Finally, the results showed that the indirect effect of teacher affective support on academic performance by the mediating role of academic adjustment was significant. These results are in line with those of studies performed by Wentzel et al. (2010) [29], and Sharhani (2016) [31]. Perceptual characteristics of teacher support, such as appreciation, listening, and respect, are associated with high self-esteem and low depression level among high school students regardless of their gender [35]. In general, it seems that teacher support can improve the student/school relationship, which can increase the students' psychological/affective well-being, as well as improving their academic adjustment. Regarding this, the chances of improving academic performance will increase. It should be noted that there were some limitations in the implementation of this research, including the use of questionnaires, sample size, and the method of research (i.e., crosssectional). Therefore, other measuring methods and instruments, such as interviewing with 
questionnaires, increasing the statistical population, and using longitudinal studies, should be used to properly explain the underlying reasons for the growth or decline of academic performance at different educational levels.

\section{Conclusions}

The results of this study showed that in addition to the teacher affective support, academic adjustment, psychological sense of school membership, and some aspects of academic identity had a significant effect on students' academic performance. Furthermore, the findings indicated that academic identity (except for foreclosure identity), psychological sense of school membership, and teacher affective support significantly influenced academic performance by the mediating role of academic adjustment.

\section{Compliance with ethical guidelines}

All participants were assured that their information would be confidential, and informed consent was obtained from all students.

\section{Acknowledgments}

The authors of this research appreciate all people who assisted in performing this study, especially the subjects.

\section{Funding/Support}

This article was derived from a $\mathrm{PhD}$ thesis submitted to Islamic Azad University, Bandar Abbas Branch. This research did not receive any specific grant from funding agencies in the public, commercial, or not-for-profit sectors.

\section{Conflicts of Interes}

The authors declare that there is no conflict of interest.

\section{References}

1. Xu X, Wang J, Peng H, Wu R. Prediction of academic performance associated with internet usage behaviors using machine learning algorithms. Computers in Human Behavior. 2019; 98:166-73. [DOI:10.1016/j.chb.2019.04.015]

2. Dilcher K, Vignat C. General convolution identities for Bernoulli and Euler polynomials. Journal of Mathematical Analysis and Applications. 2016; 435(2):1478-98. [DOI:10.1016/j.jmaa.2015.11.006]

3. Ufkes EG, Calcagno J, Glasford DE, Dovidio JF. Understanding how common ingroup identity undermines collective action among disadvantaged-group members. Journal of Experimental Social Psychology. 2016; 63:26-35. [DOI:10.1016/j.jesp.2015.11.006]

4. Cote JE, Mizokami S, Roberts SE, Nakama R. An examination of the cross-cultural validity of the Identity Capital Model: American and Japanese students compared. Journal of Adolescence. 2016; 46:76-85. [DOI:10.1016/ j.adolescence.2015.11.001] [PMID]

5. Dashper K, Fletcher T. 'Don't call me an academic': professional identity and struggles for legitimacy within the vocational field of events management higher education. Journal of Hospitality, Leisure, Sport \& Tourism Education. 2019; 25:100201. [DOI:10.1016/j.jhlste.2019.100201]

6. Gazidari E, Gholamali Lavasani M, Ejei J. The relationship between academic identity and self-regulation learning strategies with academic procrastinate students. Journal of Psychology. 2016; 19(4):346-62.

7. Fidan T, Oztürk I. The relationship of the creativity of public and private school teachers to their intrinsic motivation and the school climate for innovation. Procedia-Social and Behavioral Sciences. 2015; 195:90514. [DOI:10.1016/j.sbspro.2015.06.370]

8. Gaete J, Rojas-Barahona CA, Olivares E, Araya R. Brief report: association between psychological sense of school membership and mental health among early adolescents. Journal of Adolescence. 2016; 50:1-5. [DOl:10.1016/ j.adolescence.2016.04.002] [PMID]

9. Gray DL. Is psychological membership in the classroom a function of standing out while fitting in? Implications for achievement motivation and emotions. Journal of School Psychology. 2017; 61:103-21. [DOI:10.1016/j.jsp.2017. 02.001] [PMID]

10. Mirzabeigi A, Bakhtiarpour S, Eftekhar saadi Z, Makvandi B, Pasha R. Comparison of educational vitality, feeling of belonging to the school, the motivation of academic achievement among male and female students of secondary schools in Ilam. Quarterly Journal of Research in Educational Systems. 2018; 12(4):1085-104.

11. Asarta CJ, Schmidt JR. Comparing student performance in blended and traditional courses: Does prior academic achievement matter? The Internet and Higher Education. 2017; 32:29-38. [DOI:10.1016/j.iheduc.2016.08.002]

12. Sakiz G, Pape SJ, Woolfolk Hoy A. Teacher affective support and its impact on early adolescents. Annual Meeting of the American Psychological Association, San Francisco; 2007.

13. Perry KE, Donohue KM, Weinstein RS. Teaching practices and the promotion of achievement and adjustment in first grade. Journal of School Psychology. 2007; 45(3):269-92. [DOI:10.1016/j.jsp.2007.02.005]

14. Birman D, Tran N. When worlds collide: Academic adjustment of Somali Bantu students with limited formal education in a US elementary school. International Journal of Intercultural Relations. 2017; 60:132-44. [DOI:10.1016/j.ijintrel.2017.06.008]

15. Sadoughi M. The Relationship between academic selfefficacy, academic resilience, academic adjustment, and academic performance among medical students. Education Strategies in Medical Sciences. 2018; 11(2):7-14. [DOl:10.29252/edcbmj.11.02.02]

16. Kline RB. Principles and practice of structural equation modeling. $3^{\text {rd }}$ ed. New York: Guilford Press; 2010.

17. Sinha AK, Singh RP. The adjustment Inventory for school students (AISS). Agra (India): National Psychological Corporation; 1993.

18. Fooladchang M. The role of family patterns in adolescent adjustment. Journal of Family Research. 2006; 2(7):209-21.

19. Saghi MH, Rajaei AR. The relation between juveniles perception of family performance and their adjustment. Journal of Clinical Psychology Andishe Va Raftar. 2009; 3(10):71-82.

20. Rahiminezhad A, Farahani H, Amani H, Haddadi P, Zarpour S. Developing Academic Identity Statues Scale (AISS) and studying its construct validity on Iranian students. ProcediaSocial and Behavioral Sciences. 2011; 15:738-42. [DOI:10.1016/j.sbspro.2011.03.175]

21. Ye F, Wallace TL. Psychological sense of school membership scale: method effects associated with negatively worded items. Journal of Psychoeducational Assessment. 2014; 32(3):202-15. [DOI:10.1177/0734282 913504816]

22. Sakiz G, Pape SJ, Hoy AW. Does perceived teacher affective support matter for middle school students in mathematics classrooms? Journal of School Psychology. 2012; 50(2):23555. [DOI:10.1016/j.jsp.2011.10.005] [PMID]

23. Sadat Hosseyni F, Khayer M. Examining the role of teacher in mathamathcal academic emotional regulation of students. Journal of Psychology. 2010; 20(5):47-52.

24. Chorba K, Was CA, Isaacson RM. Individual differences in academic identity and self-handicapping in undergraduate college students. Individual Differences Research. 2012; $10(2): 60-8$ 
25. Amani $\mathrm{H}$. Investigating the relationship between academic identity, goal orientation, and academic achievement in students. Tehran: University of Tehran; 2010.

26. Rezaei T, Yazdi-Ravandi S, Ghaleiha A, Seif Rabiei MA. Depression among medical students of Hamadan university of medical sciences in 2014: the role of demographic variables. Pajouhan Scientific Journal. 2015; 13(4):1-8.

27. Peng LJ, Chen X, Luo SW. Migrant children's collective selfesteem and its relationship with their sense of belonging to school. China Special Education. 2011; 19(10): 65-9.

28. Liljeberg JF, Eklund JM, Fritz MV, af Klinteberg B. Poor school bonding and delinquency over time: Bidirectional effects and sex differences. Journal of Adolescence. 2011; 34(1):1-9. [DOI:10.1016/j.adolescence.2010.03.008] [PMID]

29. Sharifi F, Marziyeh A, Jenaabadi $H$. The relationship between achievement goals and the sense of connectedness with school and subjective vitality among students. Journal of School Psychology. 2018; 6(4):99-119.

30. Wentzel KR, Battle A, Russell SL, Looney LB. Social supports from teachers and peers as predictors of academic and social motivation. Contemporary Educational Psychology. 2010; 35(3):193-202. [DOI:10.1016/j.cedpsych.2010.03.002]

31. Hughes J, Kwok OM. Influence of student-teacher and parent-teacher relationships on lower achieving readers' engagement and achievement in the primary grades. Journal of Educational Psychology. 2007; 99(1):39-51. [DOI:10.1037/0022-0663.99.1.39] [PMID] [PMCID]

32. Sharhani M. The causal relationship between teacher emotional support and classroom communication with school well-being mediated by academic motivation. Kermanshah: Razi University; 2016.

33. Perera HN, Mcllveen P, Oliver ME. The mediating roles of coping and adjustment in the relationship between personality and academic achievement. British Journal of Educational Psychology. 2015; 85(3):440-57. [DOI:10.1111/bjep.12084] [PMID]

34. Solemani Far O, Shabani F. The relation of self-efficacy and achievement motivation with academic adjustment of first year undergraduate students of Shahid Chamran University Ahvaz. Journal of Educational Psychology Studies. 2013; 10(17):83-104.

35. Beaumont SL. Identity processing and personal wisdom: an information-oriented identity style predicts self-actualization and self-transcendence. Identity: An International Journal of Theory and Research. 2009; 9(2):95-115. [DOI:10.1080/ 15283480802669101] 